\title{
O AUDITÓRIO HETEROGÊNEO E A CONSTRUÇÃO DE UMA NAÇÃO POR MEIO DO ÁLBUM DE FOTOGRAFIAS FETES EN ISRAEL, 1951
}

\author{
Galia Yanoshevsky ${ }^{\mathrm{i}}$
}

Resumo: Este artigo revisita a noção de auditório heterogênea, de Perelman \& Olbrechts-Tyteca, por meio de um estudo de caso: Fêtes en Israël, 1951. Embora, originalmente, de iniciativa priva, esse álbum de fotografias encontra-se profundamente imerso nos valores e nos objetivos da nação nascente, como são expressos no programa governamental de educação nacional ou na Hasbara. Logo, ele pode ser lido como um documento que tenta fazer seu auditório aderir a uma tese; contudo, sua composição é heterogênea, abarcando tanto imigrantes quanto judeus da diáspora, assim como pessoas de outra família de nações, potencialmente favorável à empreitada sionista. O propósito deste artigo é, portanto, explorar de que maneira uma comunidade imaginária do "Povo de Israel" é criada, considerandose a combinação sofisticada de textos e de fotografias que atingem, simultaneamente, outras audiências.

Palavras-chave: Imaginário da nação. Auditório heterogêneo. Heterogeneidade. Álbum de fotos.

\begin{abstract}
This paper revisits Perelman \& Olbrechts-Tytecha's notion of composite audience through the case study of Feasts \& Festivals in Israel, 1951. Though originally of private initiative, this photobook is deeply immersed in the values and objectives of the nascent nation, as they are expressed in the government's national education program or by the Hasbara. It can therefore be read as a document attempting to have its audience adhere to a thesis, but this audience is composite, composed of both immigrants and Jews in the diaspora, as well as others from the family of nations, potentially favorable to the Zionist enterprise. The purpose of this article is therefore to explore the way in which the imaginary community of the "People of Israel" is created through a sophisticated combination of texts and photographs, one that allows to simultaneously appeal to other audiences as well.
\end{abstract}

Keywords: Imagined communities. Composite audience. Photobook 
EID\&A - Revista Eletrônica de Estudos Integrados em Discurso e Argumentação, Ilhéus, n. esp. ADARR, mai.2016.

Introdução - construir o auditório ou o auditório heterogêneo

A problemática do auditório não cessa de lançar desafios aos pesquisadores. Se, no caso do auditório homogêneo, o orador fala diante de um auditório que compartilha os mesmos valores (basta então, teoricamente, recuperá-los e levá-los em consideração), é o contrário se os âmbitos da argumentação ou o auditório for heterogêneo ou combinado por diferentes pontos de vista e tendências. Nos termos de Perelman e Olbrechts-Tyteca, (1992 [1958], p. 28), trata-se de um auditório que reúne pessoas diferentes em caráter, vínculos ou funções. O grande orador deverá recorrer a uma multiplicidade de argumentos a fim de cativar seu público, levando em conta sua variedade. Ele também precisa, eventualmente, considerar a maneira pela qual cada um de seus ouvintes representa em si mesmo múltiplos grupos (ibid): por exemplo, uma mulher que é simultaneamente cantora, mãe e esposa, além de ser membro de um sindicato e coach. Dirigindo-se a um auditório heterogêneo, o orador deve - em função de sua missão (pois não se concebe o conhecimento do auditório, dixit Perelman, de modo independente daqueles meios suscetíveis de agir sobre ele, p. 30) - dividi-lo ou, ao contrário, reuni-lo em subgrupos.

Como se coloca então esta questão quando se trata da fundação de uma nação e da legitimação de um povo vindo dos quatro cantos do mundo para a Terra de Israel? Como representar esse povo tão díspar em sua história para Ihe mostrar que constitui um povo e que sua História é comum? Além do mais, como tornar esta história inteligível e aceitável para aqueles que, pertencendo a essa coletividade emergente, não fizeram ainda sua Aliyah'? E como justificar o empreendimento sionista aos olhos daqueles que não pertencem ao povo judeu mas que, como no exemplo das Nações Unidas, se preocupam com a questão? Quais estratégias retóricas adotar para se dirigir a um auditório tão heterogêneo e estratificado?

Tais são as questões que emergem da leitura do volume Fêtes en Israël (1951), um photobook da iniciativa privada, pertencente à série - trilíngue (hebreu, inglês, francês) - de volumes de L'Encyclopédie d'Israël en Images, editado por Klinov no início dos anos cinquenta em Israel ${ }^{2}$. Como se trata dos anos fundadores do jovem Estado, também se trata da maneira pela qual a construção da nação tal como a concebe Anderson (1983, p. 6), ou seja, como

1 Este termo designa o ato de imigração para a Terra Santa por um judeu.

2 Sobre o conjunto de volumes, cf. Yanoshevsky, in Reverseau (ed.), à paraître. 
EID\&A - Revista Eletrônica de Estudos Integrados em Discurso e Argumentação, Ilhéus, n. esp. ADARR, mai.2016.

uma comunidade política imaginária, desempenha um papel na modelação do auditório e na maneira de construir uma história mítica da nação (ZERUBAVEL, 1995, p. 216).

No quadro deste artigo, trata-se, pois, de revisitar o problema do auditório heterogêneo a partir de um corpus textual híbrido, simultaneamente verbal e visual - a saber, o álbum de fotos que participa da construção de um imaginário da nação, aquela do povo judeu que retorna à sua terra. Mais particularmente, explorarei a maneira como a evocação e a descrição - verbal e visual - das festas e dos dias de comemoração participam da modelação de uma nação, dirigindo-se a um público heterogêneo, numa publicação que não se origina diretamente da propaganda, na medida em que pertence ao setor privado, mas que participa dela de fato, porque adere aos objetivos nacionais. Utilizarei os métodos próprios à análise argumentativa da imagem que se ligam aos procedimentos retóricos e à maneira pela qual texto e imagem trabalham conjuntamente na elaboração de uma tese. Este estudo se inscreve, por isso, no conjunto dos trabalhos do grupo ADARR ${ }^{3}$, que comungam uma abordagem simultaneamente retórica e discursiva, e que se interessam por corpora diversificados.

\section{Contexto político-histórico e pedagógico}

O aparecimento dos volumes de L'Encyclopédie entre 1950-1952, nos quais se encontra o álbum Fêtes en Israël, coincide com os primeiros anos do Estado de Israel, fundado como resultado de um mandato britânico ${ }^{4}$. Esse período se caracteriza por uma imigração judaica importante ${ }^{5}$ (I'Aliyah) a partir de 1890 (ano da primeira Aliyah), considerada mais tarde - depois da chegada dos nazistas ao poder - como uma missão de resgate de refugiados judeus da Europa ocidental e oriental, mas também do Oriente Próximo e da Ásia. As correntes de imigração fazem da população judaica em Israel um mosaico de culturas, reunindo, sobre a mesma terra, de laicos a religiosos e ainda judeus ligados à tradição, asquenazins e sefarditas ${ }^{6}$, em diversas formas

3 Análise de Discurso Argumentação \& Retórica.

4 Entre 1917 e 1948, a Grã Bretanha, segundo a Declaração Balfour (1917), foi depositária de um mandato cujo objetivo era construir um lar judaico, simultaneamente evitando conflitos com as populações já presentes no lugar.

5 Entre 1917 e 1948, a população judaica em Israel passa de 55000 a 600000 pessoas.

6 A denominação asquenazin ou asquenazi (em português) ["ashkénaze"] se aplica aos judeus da Europa ocidental, central e oriental de origem e língua alemã por oposição àqueles que são 
EID\&A - Revista Eletrônica de Estudos Integrados em Discurso e Argumentação, Ilhéus, n. esp. ADARR, mai.2016.

de colonização urbanas (cidades como Jerusalém, Tel-Aviv, Be'ersheva) ou agrícolas (Kibbutzim, Moshavim ${ }^{7}$ ). Assim, quando da fundação do Estado, em 1948, Ben Gurion, preocupado com o sucesso da fundação de um Estado sobre a base de uma população dividida em seus valores, toma a decisão de um statu quo entre religiosos e laicos, e opta pela integração da religião ao seio da legislação estatal ${ }^{8}$. Disso se segue que as festas religiosas adquirem o estatuto de festas nacionais. Acrescentam-se a elas os dias de comemoração e as festas nacionais strictu sensu, como o Dia da Independência - 5 Be'Yiar (maio de 1948).

As preocupações de Ben-Gurion se refletem igualmente no programa de educação, que reflete o desejo de integrar valores ligados tanto à tradição e ao patrimônio judaico quanto aos valores laicos de colonização e à missão de integração dos imigrados ao desenvolvimento do país. Assim, o programa educativo dos liceus e das escolas do sistema nacional de 1954 considera que o papel do ensino da História é inculcar nas crianças a História nacional - o que é típico de nações nascentes que desejam justificar sua luta pela independência e soberania (KIZEL, 2008 [2006], p. 25). Segundo o primeiro ministro israelense da educação e cultura, Ben-Zion Dinur, "se quisermos assimilar as diferentes ondas de imigração e fundi-las numa entidade nacional e cultural única, é forçoso termos uma norma" (MATHIAS, 2002, p. 17, citado em KIZEL, 2008, p. 25). Essa "norma" da educação nacional se fundamenta sobre "os valores da cultura de Israel e as realizações científicas, o amor à pátria e a fidelidade ao Estado de Israel, sobre a crença no trabalho agrícola e artesanal, a formação pioneira e a vontade de formar uma sociedade fundada sobre os valores de liberdade, igualdade, auxílio mútuo e amor ao outro" (programa de ensino, 1953).

Um dos objetivos do programa é ensinar aos alunos que, "durante 2000 anos de diáspora, nosso povo soube preservar sua religião, seus costumes, suas opiniões [...]" (Ibidem p. 27). Desse modo, o programa anuncia a vontade de desenvolver com os alunos o reconhecimento da superioridade da Torah de Israel, a visão de seus profetas, a aprendizagem da Torah e a prática da religião, além da crença profunda na eternidade de Israel (Ibidem). Do

\footnotetext{
originários da Espanha e são conhecidos como sefarditas ["séfarade"] (http://www.universalis.fr/encyclopedie/ashkenaze/).

7 Cidades de operários.

8 Em 1947, o Primeiro Ministro David Ben-Gurion envia a carta conhecida como «statu quo» ao partido religioso Agudat Israël, onde são definidas as relações entre o futuro estado e a religião. $O$ objetivo desta carta era reunir todos os judeus do país em torno da ideia da fundação do Estado.
} 
EID\&A - Revista Eletrônica de Estudos Integrados em Discurso e Argumentação, Ilhéus, n. esp. ADARR, mai.2016.

mesmo modo, Ben-Gurion sustenta uma narrativa histórico-profética que reflete um percurso histórico de longa duração. Seria necessário, segundo ele, explicar aos alunos como a nação judaica pôde sobreviver quatro mil anos (SHAPIRA, 1997, p. 228 citado em KIZEL, 2008, p. 31). Nesse sentido, o programa educativo de 1955 reflete esse desejo, determinando que

\begin{abstract}
no ensino primário, secundário e universitário, o governo garantirá o aprofundamento da consciência judaica entre a juventude israelense, seu enraizamento no passado do povo judaico e seu patrimônio histórico, e o crescimento de sua ligação moral com o judaísmo internacional, pelo reconhecimento do destino comum e da continuidade histórica que reúne todos os judeus do mundo de todas as gerações e países.
\end{abstract}

Enfim, trata-se de levar os alunos a reconhecer que a fundação do Estado de Israel é uma realização devida a múltiplas gerações de nostalgia e fidelidade e que é fruto de esforços de trabalho do grande movimento sionista ao longo de três gerações. É preciso lhes inculcar o "amor ao Estado de Israel [...], a vontade de desenvolvê-lo [...] por meio dos valores superiores da Bíblia de Israel, da visão dos profetas e dos ideais dos pioneiros" (Capítulo 5, "Education et culture", programa governamental de 3 de novembro de 1955, citado em KIZEL, 2008, p. 27-28).

2. Gênero: o Álbum de fotografias entre a memória privada e o imaginário coletivo

O livro selecionado como um estudo de caso para a presente análise pertence à família dos álbuns de fotografias. É típico de um gênero, mais conhecido por sua denominação em inglês - photobook -, muito difundido no Ocidente nos anos 1920 e 1930, entre as duas guerras mundiais, com a ascensão dos regimes totalitários. Na tradição do fotojornalismo, ele se inspira em fotógrafos soviéticos que utilizavam técnicas de fotografia narrativa, "os relatos em fotos", produzindo séries de reportagens fotografadas, com legendas explicando mais claramente seu conteúdo (SELA, 2000, p. 40). Por outro lado, é característico, como é o caso da América dos anos trinta e da França dos anos cinquenta, de nações em plena crise e/ou em reconstrução e onde existe uma necessidade de (re)estruturação do ethos nacional ${ }^{9}$. Em

9 É o caso do projeto fotográfico da seção histórica da FSA (Farm Security Administration) durante a Grande Depressão e o New Deal de Roosevelt, que, entre 1933-1944, documentou as misérias da vida dos americanos durante a Grande Depressão. É também o caso da reconstrução da imagem da França do pós-guerra, tal como foi produzida sob os cuidados da Direction de la Documentation et 
EID\&A - Revista Eletrônica de Estudos Integrados em Discurso e Argumentação, Ilhéus, n. esp. ADARR, mai.2016.

Israel, o álbum de fotografias adquire nobreza com a fundação do Estado, e participa de fato da paisagem fotográfica que estrutura a consciência coletiva israelense desde a fundação do Estado até nossos dias (RAZ, 2010, p. 45-46). Além das fotos singulares e do fotojornalismo, os álbuns de fotografias constituem a principal fonte fotográfica da época (OREN, 2007, p. 25-26). A partir de 1950, inúmeros álbuns são produzidos em Israel, com temas que incluem a seguranção do país, a política de imigração e a conquista do território.

Os álbuns de Klinov se inscrevem, então, num gênero que visa recontar a história de Israel por meio de publicações mais ou menos oficiais e mais ou menos poéticas. Assim, por exemplo, o fotógrafo Yaakov Ben-Dov publica, em 1952, um álbum de fotografias do país, igualmente com uma capa de couro e um relevo em cobre, Visage d'Israël [Ele pneï Israël] (1952), e o fotógrafo Zoltan Kluger publica um álbum sem texto. Os anos cinquenta veem 0 surgimento de inúmeros álbuns consagrados a Jerusalém e ao Sinai ${ }^{10} \mathrm{e}$, depois disso, surgirão numerosos álbuns na década (d'Israël, de Tsahal) ${ }^{11}$, álbuns de vitória depois da guerra dos Seis Dias (1967), assim como outros álbuns mais poéticos, como a Chanson du lac mourant (sobre o lago de Hula), de Peter Merom (1960), ou álbuns subjectivos/críticos, como Off the Beaten track (1953), de Beno Rothenberg.

Embora de iniciativa privada - os álbuns de Klinov, publicados pela casa de edição La'am, são patrocinados por um certo Mishkovsky, um empresário cujo objetivo é o lucro (NAHMIAS, 1997, p. 28-31) -, esses álbuns, todavia, se inscrevem numa série de publicações governamentais, entre 1951 e 1952, que compreendem também folhetos de propaganda, e utilizam fotos do Gabinete Governamental de Imprensa, dos arquivos da KKL e da Keren Hayesod, assim como imagens de fotógrafos independentes (OREN, 2005, p. 120). Podem, mais justificadamente, ser contados entre as publicações com vocação de propaganda, pois este empresário contrata como diretor dos álbuns Isaiah Klinov, antigo jornalista e diretor atual da Hasbarah do Gabinete da Imprensa

de Diffusion e de sua casa de edição, a Documentation française (Avissar, Thèse de doctorat en cours).

10 Os álbuns de Beno Rothenberg, Land of Israel, Jerusalem/Tel-Aviv, Schocken Publishing House, 1958; The Story of Jerusalem. A Pictorial report, Beno Rothenberg (dir.), David Ben-Gurion (preface), Tel-Aviv, Am Oved Publishers, 1967.

11 Oren, op. cit., 2005, p. 120-126; exemplos: Israël a dix ans, Massada Publishers, TelAviv/Jérusalem, B.Z. Löwy, Israël a vingt ans, mots et images, Tel-Aviv, Bronfman Books Publishing, 1968. 
EID\&A - Revista Eletrônica de Estudos Integrados em Discurso e Argumentação, Ilhéus, n. esp. ADARR, mai.2016.

para a Informação, a Radiodifusão e os Filmes do Ministério do Interior, e Beno Rothenberg, fotógrafo que segue de perto a fundação do Estado, documentando-a sob uma luz favorável em geral (OREN, 2007, p. 15). A vocação dos álbuns, apresentados numa encadernação de falso couro estilo Bezalel e relevo em cobre, numa luxuosa embalagem metálica, sugere uma utilização com fins lucrativos e retóricos: servem, sem dúvida, de presente aos futuros doadores e apoiadores do projeto sionista, tanto quanto um presente luxuoso oferecido a amigos ${ }^{12}$. Além dos objetivos retóricos derivados da necessidade de obter apoio dos doadores e apoiadores, o estilo de álbum Bezalel $^{13}$ sugere uma tentativa de produzir um espaço de memória coletiva que imite o estilo de álbum de família e que possa servir de memória nacional personalizada para cada indivíduo que possua a coleção ou participe da empresa sionista.

A seguir, estudo o álbum Fêtes en Israël [Festas em Israel], explorando a maneira como a combinação de texto e imagem exerce um papel na estruturação de um imaginário comunitário, como compreendido por Anderson (1983, p. 6) e Martins (2010) ${ }^{14}$, para quem a fotografia está ligada ao fenômeno mais amplo dos discursos de identidade nacional. Eu me interesso também pelo modo como a memória individual dos participantes da empresa sionista - tão diferentes em suas origens, crenças e modos de vida - é modelada pelo pertencimento a esse coletivo em plena formação do qual o álbum é testemunha. Ao mesmo tempo, trata-se de ver como este dispositivo pode se dirigir igualmente àqueles que não participam diretamento do projeto, mas que se preocupam com ele, como o povo judeu que permanece na diáspora e os membros de outras nações. Trata-se, em suma, de ver quais as estratégias empregadas para se dirigir ao auditório heterogêneo.

\footnotetext{
12 Não pudemos, até o momento, trabalhar pessoalmente nos arquivos da casa de edição La'am. Mas, considerando as condições materiais modestas da época e o fato de se tratar de uma edição de luxo de acordo com os padrões de então, é muito provável que fosse a utilização prevista para este tipo de objeto de valor.

13 Álbuns artesanais da Escola de Belas-Artes, Bezalel, foram concebidos para organizar fotos de família.

14 "Naquelas imagens, podemos realmente ver certos aspectos do país: suas paisagens, suas fisionomias, seu povo, etc. [...] as fotos permitem aos habitantes de certo lugar se ver e ver seu próprio país, ao mesmo tempo que dão uma representação do mesmo país para os estrangeiros" (MARTINS, 2010, p. 86).
} 
EID\&A - Revista Eletrônica de Estudos Integrados em Discurso e Argumentação, Ilhéus, n. esp. ADARR, mai.2016.

\section{Análise de Fêtes en Israël}

Esta análise busca distinguir os traços discursivos do contexto históricopolítico e da abordagem pedagógica defendida pela Instituição no início dos anos cinquenta em Israel, o que contribui para a estruturação de uma narrativa mítica da nação transmitida aqui pela história das festas nacionais. Passo em revista todos os elementos visuais e verbais: os prefácios, as legendas, a tipografia e as imagens, suscetíveis de participar deste empreendimento.

\subsection{O prefácio - o passado mítico inscrito no presente}

Introduzida de modo explícito no início, a tese do álbum consiste em dizer que a celebração das festas pelas gerações do povo de Israel é reveladora do êxito do projeto sionista: recuperar o país, fazer "florir o deserto", soldar uma nação a partir de um povo disperso, pois, as festas, se acreditarmos em Klinov, constituem uma força unificadora para a nação que renasce "no país de seus ancestrais e no quadro do novo Estado" (Fêtes en Israël, p. 5).

Segundo ele, elas são "bordada(s) com uma linha triplamente brilhante ${ }^{15}$ - religiosa, histórica e nacional”, que jamais foi esquecida na Diáspora, onde se continuaram a celebrar as festas a despeito de perturbações diversas. Com "a revolução do retorno a Sião", com a libertação do país e o estabelecimento do Estado, o caráter das festas sofreu uma modificação profunda: as formas antigas são conservadas, mas "novos desenvolvimentos históricos, novos ramos verdes e frescos se põem a pulsar sobre o velho tronco, durante longo tempo ressecado" (Ibidem, p. 6) ${ }^{16}$.

O objetivo do álbum consiste então em representar em imagens o Estado de Israel e seus habitantes à luz das festas reinterpretadas: trata-se de mostrar dessa forma a nova importância das festas e o conteúdo a elas conferido pelo jovem Estado: a Festa da liberdade (Páscoa), aquela das primeiras plantas (Tabernáculo), da colheita (Festa das sete semanas). São formas tradicionais investidas de novas significações e celebradas por pessoas de todas as idades, etnias e estratos sociais confundidos (Ibidem).

15 Metáfora que faz alusão à maneira "artesanal" de "fabricar" um povo. 16 Metáfora do crescimento natural e da regeneração. 
EID\&A - Revista Eletrônica de Estudos Integrados em Discurso e Argumentação, Ilhéus, n. esp. ADARR, mai.2016.

A ênfase é colocada sobre a unificação na diversidade, sobre o coletivo e a participação massiva. Cada um participa da festa, mas a celebração varia segundo as comunidades e os modos de vida diversos (Ibidem, p, 7): assim, sefardistas e asquenazins celebram segundo os ritos de sua própria tradição. Enquanto alguns festejam na intimidade de seus lares, os coletivos, como os Kibutz, ou as estruturas sociais, como o exército, as celebram, pelo contrário, na coletividade. A festa coletiva é apresentada neste prefácio como "um dos signos do renascimento que se opera em nossa pátria" (Ibidem). Os limites das festas tradicionais são ultrapassados pela inserção de um conteúdo novo que reflete a atualidade dos acontecimentos e das emoções, e onde os novos ritos - como excursões a sítios históricos, concursos esportivos, corridas de tochas ou oferenda de primícias na Shavouot ${ }^{17}$ - tornam-se parte integrante da tradição. Além disso, elas suscitam uma participação massiva (Ibidem, p. 8).

As festas alegres são conjugadas com jornadas de comemoração das tragédias da nação num passado longínquo e recente, como os dias da destruição do Templo e o dia da Shoah. Por outro lado, novas festas se estabelecem, como aquela do dia da independência, ligada a uma vida (mítica) "antiga e livre": "A Festa do Estabelecimento do Estado ocupa o lugar de honra que merece: é uma jornada de felicidade e alegria, mas também de tomada de consciência nacional" (p. 9).

Enfim, o álbum representa, também por suas imagens, as diferentes maneiras de tecer os laços entre a geração presente e a terra dos ancestrais ${ }^{18}$, que passa tanto pela cultura do patrimônio (objetos rituais expostos nos museus) como pela cultura popular (por exemplo, os festivais de dança).

O papel das imagens consiste em provocar ou acrescentar, segundo a fórmula cara a Perelman, a adesão dos espíritos às teses que se thes apresentam ao assentimento (PERELMAN; OLBRECHTS-TYTECA, 1992 [1958], p. 5), no caso do leitor do povo judeu - que já fez seu Aliyah, ou daquele que ainda habita a Diáspora:

Nós o destinamos tanto aos olhos quanto ao espírito do leitor e esperamos sinceramente que estas belas imagens - todas difundindo o conhecimento da

17 Festa das sete semanas.

18 Sobre a questão da inscrição do passado no presente de uma nação, esboçando o portrait de um país, cf. David Martens, in: Reverseau (ed.) a ser publicado: "Dessa forma, se o gênero [portrait de país] tende a incluir considerações sobre a história do país que ele retrata, elas estão, na maioria das vezes, subordinadas à apresentação do país tal como se apresenta nos dias de hoje. Permanece o fato de que um país é, com efeito, uma entidade que se define em função de uma inscrição na duração que deve ser considerada". 
EID\&A - Revista Eletrônica de Estudos Integrados em Discurso e Argumentação, Ilhéus, n. esp. ADARR, mai.2016.

própria alma de nosso país, servirão para reaproximar os corações judaicos por todo o mundo, inspirando-lhes o amor pelo Estado de Israel (p. 10).

\subsection{Tipografia}

A vontade de trazer o passado atual para o presente se manifesta também na escolha tipográfica do título. Fêtes en Israël (figura 1) está escrito como uma inscrição asquenazin básica em estêncil, no estilo "Stam" de Francesca Baruch, estilo de influência histórica (SPITZER, 2012). Ele é decorado simultaneamente pela forma de um rolo, emblema da Torah, e por ramos de oliveira, árvore típica da terra de Israel e símbolo universal da paz. Este formato tipográfico sugere a ligação com um passado histórico, mas também uma vontade de conjugar valores tradicionais e específicos ao povo judaico (simbolizado pelo rolo da Bíblia), com valores universais (simbolizados pelos ramos de oliveira).

\section{Figura 1 - 0 mercado dos loulavim e étroguimes}

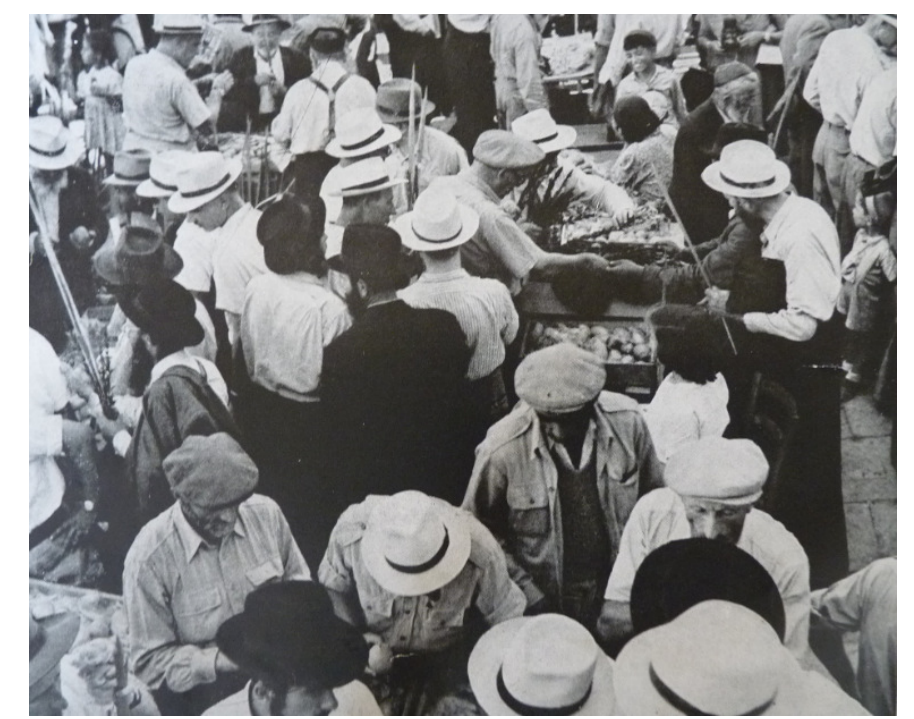

Fonte: Klinov, I. (éd.), Fêtes en Israël, La'am: Tel-Aviv, 1951, p. 21

\subsection{Fotografias}

As imagens variam em torno do tema, gênero e ângulo da câmera: os retratos (imagem de perfil de um judeu tradicional que toca o shofar ${ }^{19}$, p. 11; uma mulher acendendo as velas de shabbat, p. 139, fotografada de baixo para cima, para simbolizar a grandeza desse dia), objetos rituais (nos museus, p. 18;

19 O shofar é um instrumento musical de sopro usado nos rituais israelitas desde a Antiguidade. 
EID\&A - Revista Eletrônica de Estudos Integrados em Discurso e Argumentação, Ilhéus, n. esp. ADARR, mai.2016.

cartões de votos para o ano novo, p. 12; rolos, shofars, ramos de palmeira, p. 19; velas do Hannouca, p. 33), competições esportivas (a Macchabiade, os jogos olímpicos judeus, p. 26-27), ritos executados nos lugares públicos (a cerimônia do Tashlich [esvaziar os bolsos no mar] na praia, p. 16; a festa da arborização e das plantações, p. 50-51), e os lugares simbólicos (Le Kotel [muro das lamentações]), p. 133, com um zoom sobre as pedras e suas inscrições; a corrida de tochas dos jovens soldados de Modiin, próxima dos túmulos de Hashmonaim na direção de Jerusalém, p. 42-43 - fotos que simbolizam a tradição de revolta representada pela passagem da tocha de uma geração a outra (a casa dos Hashmonaim, que se revoltou contra os gregos e a geração atual revoltada contra toda ocupação), ritos populares (danças campestres na Páscoa, p. 72; dança das oferendas, p. 102).

Por outro lado, o álbum destaca ritos festivos domésticos de etnias diferentes e em diversos quadros e instituições sociais. A título de exemplo, veem-se as velas de Hannouca acendidas tanto por asquenazins quanto por sefarditas, tanto por mulheres quanto por homens, na sinagoga, nos campos de imigrantes, nos jardins de infância e pelos soldados. Nota-se também a confusão proposital entre as velas de Hannouca e do Ménorah ${ }^{20}$, acendidas perto do túmulo do rei David, para simbolizar a continuidade entre um passado de revolta e de liberdade e o presente (p. 36-41); o Seder ${ }^{21}$ é representado por fotos tiradas nos campos de imigrantes e no refeitório no Kibutz (p. 74-75), mas também nos lares tradicionais dos judeus da Arábia (p. 76).

As imagens de multidões ocupam um lugar central no volume. Nós as vemos se preparando para a festa (no mercado de lulavim e étroguim ${ }^{22}$, p. 21; nas peregrinações a Jerusalém, p. 28, p. 77) ou celebrando (a festa de SimhatTorah $^{23}$ na Grande Sinagoga de Tel-Aviv, p. 32). São representadas nos momentos de júbilo (o cortejo de Purim, p. 60), também nos momentos de luto (a transferência das cinzas dos mártires judeus dos fornos crematórios nos campos de extermínio na Europa, p. 48). Juntas, essas imagens de multidões dão ideia de uma coletividade, de um grupo social unido nas festas acima das diferenças individuais de idade, sexo, crença e etnia. Nas fotos de multidão, notamos também diferenças individuais simbolizadas por objetos

20 Candelabros com sete braços, símbolo do Templo.

21 Jantar de Páscoa.

22 Ramos de palmeira e limões tradicionais.

23 Regozijos da Torah. 
EID\&A - Revista Eletrônica de Estudos Integrados em Discurso e Argumentação, Ilhéus, n. esp. ADARR, mai.2016.

das vestimentas, tais como os diferentes chapéus (coberturas de cabeça) que usam os laicos (fedoras) ou os religiosos (chapéus pretos ou o kipá).

As fotos relativas ao dia da Independência, a festa nova que significa a passagem da antiguidade para o presente, coroando, portanto, todas as outras festas segundo o prefácio, se estendem ao longo de 23 páginas (p. 106-128): um sétimo volume é consagrado a ela. Começando pelo emblema do Estado de Israel: ainda que marcando uma separação nítida entre um passado sem estado e um presente estatal, ele enfatiza, contudo, a continuidade entre o passado outrora corajoso e livre, representado pela Menorah, símbolo do templo e do antigo regime do Reino da Judeia. São mostrados os fogos de artifício (p. 107 e 128) e as preces de graças em honra da festa, laica. No entanto, a religiosidade deste momento laico é representada, entre outras coisas, por um retrato (Figura 2) do primeiro ministro, Ben-Gurion, vestindo um terno e com um chapéu alto na cabeça, na tradição inglesa, pronunciando uma prece de graças para comemorar a independência (p. 109). Observamos, então, como, fiéis ao paradigna de status quo imposto por Ben-Gurion, em 1947 (cf. supra), conteúdos laicos se inscrevem na nova História do povo judeu, aderindo, no entanto, às coerções da tradição religiosa judaica. O dia da Independência também é representado pelas manifestações diplomáticas (p. 110- 113), simbolizando o reconhecimento do Estado de Israel pelas Nações Unidas.

Figura 2 - David Ben Gurion assiste às orações de graças na sinagoga no Dia da Independência

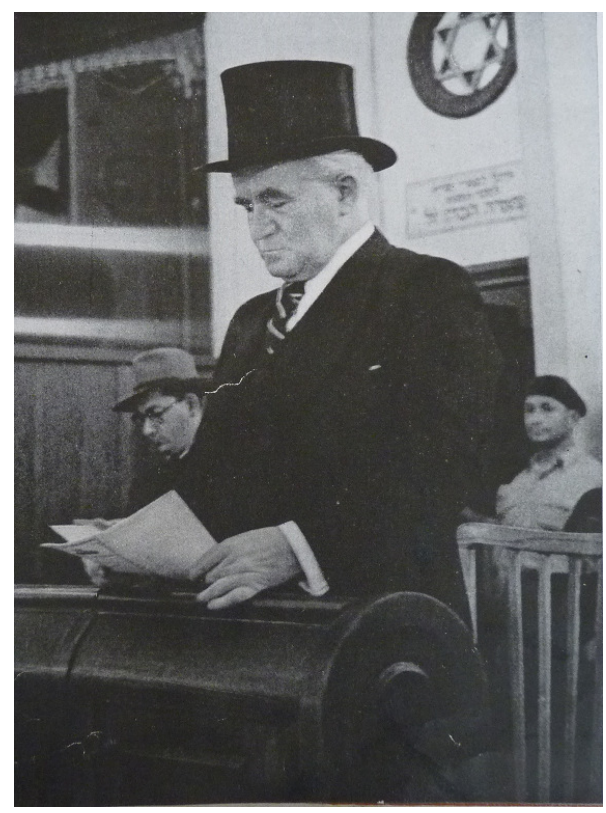

Fonte: Klinov, I. (éd.), Fêtes en Israël, La'am: Tel-Aviv, 1951, p. 108. 
EID\&A - Revista Eletrônica de Estudos Integrados em Discurso e Argumentação, Ilhéus, n. esp. ADARR, mai.2016.

No volume, opera-se um deslizamento entre as festas da Independência e a capital, Jerusalém (p. 116-126). Enquanto todo o país recebeu sua independência, este não é o caso de Jerusalém, que permanece, depois da guerra da Independência de 1948, uma cidade dividida. Ela é representada, no volume, como lugar simbólico do presente (por exemplo, lugar das marchas da Independência e sítio da sepultura do profeta do Estado judaico, Herzl, p. 129), mas também como lugar ao mesmo tempo concreto e mítico, onde se funde uma visão da cidade concreta àquela Jerusalém eterna, tema de nostalgia desde a Diáspora ("se eu te esquecer, Jerusalém, que minha direita se esqueça dela mesma", juramento pronunciado pela multidão ao redor do túmulo de Herzl, p. 132). Esta mesma imagem é exaltada por uma foto de zoom diante das pedras do Muro das Lamentações, por ocasião de 9 Av, dia da destruição do Templo (p. 133): trata-se de produzir um lugar de memória ligado a um passado glorioso que deixou de existir e que até o momento não foi, todavia, completamente restabelecido (a antiga cidade não está ainda libertada). É o mesmo que acontece com a foto da Torre de David, tirada por um ângulo de baixo para cima, uma maneira de valorizar a resistência judaica aos romanos, por meio da última torre que permaneceu de pé depois da destruição do Templo.

Enfim, um último fator que reúne todas as facções da sociedade israelita nascente é o dia de feriado dominical, o Shabbat, também ele fundamentado no documento do statu quo de Ben-Gurion. Aqui ele é representado tanto por seus ritos tradicionais (acender as velas, p. 139, o jantar e as preces de Shabbat, p. 143) como por seus ritos sociais e laicos: a interrupção de todo trabalho (p. 141), o relaxamento no kibutz (p. 146) e na praia (p. 147).

\subsection{A legenda}

Participante ativa da formulação da tese do volume, a legenda trabalha com a imagem, ancorando a mensagem dela numa interpretação particular ${ }^{24}$. Os títulos são portadores de explicações que participam do programa geral do volume. Assim, por exemplo, a foto do judeu tocando o Shofar (p. 11) está acompanhada de uma legenda que diz "Repercutidos, cor de nossa liberdade". O shofar, designado por soar e "abrir o céu" para que Deus aceite a prece dos mortais, é aqui transformado em instrumento de libertação do povo judeu, ideia que coroa o volume inteiro. Da mesma forma, os votos de significados de modo a combater o terror dos significados incertos [... ]" (BARTHES, 1964, p. 44). 
EID\&A - Revista Eletrônica de Estudos Integrados em Discurso e Argumentação, Ilhéus, n. esp. ADARR, mai.2016.

felicidade para o novo ano não são simples votos: eles ilustram "tanto os antigos costumes como as aspirações novas do país" (p. 12).

O sentimento suscitado e evocado pelas fotos e, de participação massiva nos ritos, é secundado por legendas que repetem a palavra "multidão" (p. 16, 17, 147 etc.). A ênfase é colocada sobre as diversas etnias que participam dos ritos (A decoração variada dos tabernáculos distingue as diferentes comunidades, Tabernáculo asquenazin, Tabernáculo boucariano [boukharien] p. 24-25); as diversas comunidades e tipos de habitação ("Nos campos de trabalhos dos novos imigrantes, eles vêm de todos os cantos do mundo; é sua primeira festa em sua antiga e nova pátria", p. 38; "Numa cidade coletiva, a sala de jantar é decorada e as mesas são cobertas pelo Seder", p. 75). Mas, ao mesmo tempo, a ênfase é colocada também sobre a experiência particular de cada um, homem e mulher, que participa da missão nacional ("Uma mãe de luto planta uma jovem árvore em memória de seu filho heroico”, p. 55).

Termos hiperbólicos são empregados para mostrar a excitação e a emoção em todas as atividades ligadas à preparação da festa ("uma grande agitação reina no mercado de loulavim e étroguim, p. 20; nós escolhemos os exemplares mais bonitos, p. 23). Como se as fotos não possuíssem poder persuasivo suficiente para provocar a identificação dos espectadores, as emoções são frequentemente formuladas expressamente nas legendas ("O desfile militar solene é impacientemente esperado nas ruas de Jerusalém”, p. 115; "expectativa feliz das crianças esperando o desfile", p. 117).

Enfim, citações bíblicas ligam o presente ao tempo mítico do passado judaico: "E no primeiro dia apanhareis o fruto da bela árvore [...] e vos regozijareis durante sete dias perante o Eterno" (Levítico, XXIII, 40), p. 19; "Tu visitas a terra e depois que a alterares, tu a regarás abundantemente, os regatos de Deus estarão repletos de água..." (Salmos, LXV, 10), p. 31, em referência à festa dos Tabernáculos, que é igualmente aquela da água. Assim, por exemplo, a festa de origem pagã de Toubishvat (le 15 Sevat), que representa o início do ano para as árvores, e que é comemorada pelas plantações massivas, é representada na legenda por uma citação bíblica ("... a fim de que nossos filhos sejam como jovens plantas que crescem em sua juventude” (Salmos, CXLIV, 12) (p. 52), enquanto que ela não figura em nenhum lugar na bíblia (ela tem origem no período posterior das interpretações orais, a mishna). Em suma, as citações bíblicas têm por objetivo integrar as festas do estado nascente no ciclo das festas tradicionais do povo judeu. 
EID\&A - Revista Eletrônica de Estudos Integrados em Discurso e Argumentação, Ilhéus, n. esp. ADARR, mai.2016.

À guisa de conclusão - "Nestes dias, neste momento" ou "unidos na diversidade"

Mostrei que todas as partes do volume - prefácio, legendas e fotos trabalham juntas para confirmar uma tese - aquela do renascimento legítimo do povo judeu. Mas, retornemos à problemática do auditório heterogêneo colocada no início: como este álbum de Klinov, que apresenta ao leitor as festas de Israel, clama ao assentimento de um auditório tão diverso como os imigrantes, os judeus da diáspora e as nações?

Acontece que a multiplicidade de argumentos aos quais o grande orador de Perelman deverá recorrer, a fim de cativar seu auditório, considerando a natureza heterogênea deste, é recolocada aqui por um hábil uso da combinação texto/imagem. E, de início, trata-se da coerência entre a tese apresentada no prefácio e a demonstração visual que se segue. As fotos que mostram a participação nas festas de todos os membros da sociedade, sobre a terra de Israel e nos sítios antigos (túmulos, sítios arqueológicos), assim como nos novos (cidades, kibutz, praias), estão em perfeito acordo com a tese segundo a qual as festas representam o renascimento legítimo e a continuidade de um povo corajoso e livre que ganha novamente sua terra histórica. Assim, esta tese é assegurada por sua ancoragem na mensagem visual nas legendas: os termos hiperbólicos acentuam a imagem positiva e a exaltação diante da realização do projeto sionista: a formulação verbal da emoção manifestada nas fotos sugere ao leitor o sentimento que ele deve experimentar e assegura a "boa recepção" da tese.

Ora, o grande orador perelmaniano pode também levar em consideração a maneira como cada um de seus ouvintes representa em si mesmo uma multiplicidade de grupos diferentes. De fato, para aqueles que participam ativamente do empreendimento sionista, a saber, os imigrantes que fizeram sua Aliyah e que estão representados nas fotos, este álbum pode ser recebido como um "álbum de família", uma crônica das festas das quais participam: eles são representados neste volume como mulheres e homens, filhos e pais, asquenazins e sefarditas, membros de um grupo (kibuts, burguesia, religiosos, laicos) ou indivíduos. $O$ álbum pode também, por outro lado, se dirigir aos imigrantes potenciais, que não fizeram (ainda) sua Aliyah, mas que podem, por meio deste álbum, imaginar como lhes é possível pertencer a este grupo que compartilha, desde agora, com eles uma bagagem cultural comum ao povo judaico (suas festas e seus rituais). Não é por acaso, pois, que está ausente deste volume qualquer 
EID\&A - Revista Eletrônica de Estudos Integrados em Discurso e Argumentação, Ilhéus, n. esp. ADARR, mai.2016.

outra população - árabe-muçulmana ou cristã (embora existente e mesmo mostrada em outros volumes da Enciclopédia de Israel em imagens de Klinov), que não saberia como pertencer a este povo, que tem mais coisas em comum com seus próximos na diáspora do que com aqueles com quem partilha a terra.

Enfim, o grande orador, com pleno conhecimento de seu auditório, deve dividi-lo ou, ao contrário, reuni-lo em subgrupos, em função de sua própria posição. A solução do enunciador deste volume consiste em apresentar o auditório como uma entidade "unida em sua diversidade" (fórmula transformada em nossos dias no emblema da Europa Unida). Para que todos e cada participante desse coletivo - em Israel, mas também na diáspora - possam se sentir ligados a esta comunidade imaginária, é preciso que cada um se sinta à vontade em sua diferença: donde a apresentação visual, secundada pela formulação verbal, desta diversidade cultural de todas as etnias que formam o povo de Israel e seus respectivos modos de vida.

Os outros, apoiadores reais e potenciais das nações, parecem estar excluídos desta comunidade tão diversa e, no entanto, tão unida em sua vontade de liberdade e de realização do sonho nacional. Todavia, este volume se dirige também àqueles e $\mathrm{o}$ faz de duas maneiras. De início, pela apresentação do fato acabado: a existência de fato do Estado de Israel, cujas festas confirmam a continuidade ("nestes dias, neste momento", como diz a prece de Hagada lida na refeição de Páscoa que repete a saída do Egito). A prática dos rituais da antiguidade, vividos na diáspora e integrados nas festas nacionais, apela ao argumento da continuidade, a saber, que se um processo continua sem interrupção, é porque ele é necessário. Suas manifestações atuais tornam-se então legítimas por suas realizações no passado ("é assim que sempre fizemos aqui" - é um argumento típico para justificar os rituais). $O$ argumento de continuidade aparece em Fêtes en Israël por meio do ritual das três subidas a Jerusalém. Uma segunda maneira de se dirigir aos outros, aparentemente excluídos da comunidade judaica, é por meio da inscrição desse auditório no próprio volume: ao lado dos imigrantes e dos habitantes judeus de Israel, vemos também fotos de diplomatas estrangeiros visitando Israel durante as festas da Independência, rendendo homenagem ao jovem estado. Essas imagens certificam, então, a legitimidade do empreendimento sionista aos olhos das nações e sugerem ao leitor que não pertence ao povo judaico a atitude que lhe convém adotar. 
EID\&A - Revista Eletrônica de Estudos Integrados em Discurso e Argumentação, Ilhéus, n. esp. ADARR, mai.2016.

\section{Referências}

ANDERSON, B. Imagined Communities. London: Verso, 1983.

AVISSAR. N. Between Humanist Photography and Propaganda: The Illustrated Campaign for National Reconstruction by the Documentation Française, 1946-1960. Thèse de Doctorat en cours sous la direction de Vanessa Schwartz, Université de Virginie.

BARTHES. R. La rhétorique de l'image. Communications. N. 4, 1964, p. 40-51.

LÖWY. B.Z. Israël a vingt ans, mots et images Tel-Aviv: Bronfman Books Publishing, 1968.

ROTHENBERG. B. Off the Beaten Track. Tel-Aviv: Mazpen Publishing House, 1953. . Land of Israel. Jerusalem/Tel-Aviv: Schocken Publishing House, 1958.

Publishers, 1967.

(Éd.). The Story of Jerusalem. A Pictorial report. Tel-Aviv: Am Oved

KIZEL, . Subservient History. A Critical Analysis of History Curricula and Textbooks in Israel 1948-2006. Tel-Aviv: MOFET Institute, 2008 (Hébr.).

KLINOV, I (Ed.). Fêtes en Israël. Tel-Aviv: La'am, 1951.

MARTENS, D. L'hier et l'aujourd'hui dans le portrait de pays. Neutralisations de l'historicité. In: REVERSEAU, Anne (Ed.), Lire et voir 3. Portraits de pays illustrés. Un genre phototextuel. Paris: Classiques Garnier, coll. La Revue des lettres modernes, à paraître.

MARTINS, S. S. Between Present and Past: Photographic Portugal of the 1950s. In. BAETENS, J.; STREITBERGER, A.; VAN GELDEN, H. (Eds.). Time and Photography. Leuven: Leuven University Press, 2010, p. 85-102.

MATHIAS, Y. Nationalizing Education: The Emergence of state History Curriculum. In: BEN AMOS, A. (Ed.). History, Identity and Memory: Images of the Past in Israeli Education. Tel-Aviv: School of Education and Ramot publishing House Tel Aviv University, 2002, p.15-46. (Hébr.).

NAHMIAS, Y. Histories and White Spots - the Middle Ages of Israeli Photography. Camera, n. 5, 1997, p. 28-31.

OREN, R. Constructing Place: Propaganda and Utopian Space in the Landscape in Zionist Landscape Photography, 1898-1948. Devarim Hahadim, no. 2, Jerusalem/TelAviv: Van Leer Institute and Hakibbutz Hameuchad, 1997, p. 13-31.

. System and Themes: Aspects of Jewish Landscape Photography in Eretz Israel, 1945-1963, Thèse de Doctorat, Université de Haifa, 2005. 
EID\&A - Revista Eletrônica de Estudos Integrados em Discurso e Argumentação, Ilhéus, n. esp. ADARR, mai.2016.

- Photography has taught me two things (Beno Rothenberg, «Photographer »). In. ROTHENBERG, Beno. Photographed and reported 1947-1957. Tel-Aviv: Eretz Israel Museum, 2007, p. 13-15.

PERELMAN, C.; OLBRECHTS-TYTECA, L. Traité de l'argumentation: la nouvelle rhétorique. Bruxelles: ULB, $5^{\text {ème }}$ édition, 1992 (1958).

RAZ, G. A Short History of Local Photography. Tel-Aviv: Sal Tarbut Arzi Publishing, 2010.

SELA, R. Photography in Palestine in the 1930s-1940s. Tel-Aviv: Herzliya Museum of Art, Hakibbutz Hameuchad Publishing House, 2000.

SHAPIRA, A. New Jews, Old Jews. 4ème édition, Tel-Aviv: Am-Oved, 2003 (1997).

SPITZER, M. De nos lettres, 11 novembre 2012. Disponível em: https://yaronimus.wordpress.com/2012/11/11 (Hébr.). Acesso em: 11.11.2012.

YANOSHEVSKY, G. Portrait du pays en jeune état : L'Encyclopédie d'Israël en images 19501952. In: REVERSEAU, Anne (Ed.). Lire et voir 3. Portraits de pays illustrés. Un genre phototextuel. Paris: Classiques Garnier, coll. La Revue des lettres modernes, à paraître.

ZERUBAVEL, Y. Recovered Roots, Collective Memory and the Making of Israel National Tradition. Chicago: University of Chicago Press, 1995.

Como citar:

YANOSHEVSKY, Galia. O auditório heterogêneo e a construção de uma nação por meio do álbum de fotografias Fêtes en Israël, 1951. Trad. Maria Helena Cruz Pistori. EID\&A - Revista Eletrônica de Estudos Integrados em Discurso e Argumentação, Ilhéus, n. esp. ADARR, p. 75-92, mai.2016. 